\title{
Melatonin and circadian rhythms in autism: Case report
}

\section{Gabriela Melloni Zuculo, Bruno S.B. Gonçalves, Clay Brittes, Luiz Menna- Barreto \& Luciana Pinato}

To cite this article: Gabriela Melloni Zuculo, Bruno S.B. Gonçalves, Clay Brittes, Luiz MennaBarreto \& Luciana Pinato (2017) Melatonin and circadian rhythms in autism: Case report, Chronobiology International, 34:4, 527-530, DOI: 10.1080/07420528.2017.1308375

To link to this article: https://doi.org/10.1080/07420528.2017.1308375

\section{Published online: 20 Apr 2017.}

\section{Submit your article to this journal $\llbracket$}

Llll Article views: 352

Q View related articles $\widetilde{ }$

View Crossmark data ¿

Citing articles: 2 View citing articles $₫$ 


\title{
Melatonin and circadian rhythms in autism: Case report
}

\author{
Gabriela Melloni Zuculo ${ }^{a}$, Bruno S.B. Gonçalves ${ }^{b}$, Clay Brittes ${ }^{c}$, Luiz Menna-Barreto ${ }^{b}$, and Luciana Pinato ${ }^{a}$ \\ aUniversidade Estadual Paulista (UNESP), Marília, Brazil; 'bscola de Artes, Ciências e Humanidades - Universidade de São Paulo, São Paulo, \\ Brazil; 'Laboratório de Dificuldades e Distúrbios da Aprendizagem e Transtornos da Atenção-UNICAMP, Campinas, Brazil
}

\begin{abstract}
Among the most co-occurring conditions in autism spectrum disorders (ASD), there are sleep disorders which may exacerbate associated behavioral disorders and lead to intensification of existing autistic symptoms. Several studies investigating the use of melatonin in the treatment of sleep disorders in ASD have shown comparative efficiency in sleep with little or no side effects. Here we report a case of ASD with non-24-hour rhythm and the effect of melatonin in circadian parameters by actigraphy. Visual analysis of the first 10 days recorded and the periodogram suggest that this patient showed a non-24-hour rhythm. This ASD subject showed before melatonin administration an activity/ rest rhythm lower than 24 hours. The results show that melatonin increased approximately 4.7 times the regularity of circadian activity rhythm and resting staying on average between 00:00 and 06:00 and showed positive effects in improving the quality of sleep and behavior. So, the actigraphy showed an ASD subject with a non-24-hour activity/rest rhythm which changed this rhythm to a 24-hour rhythm after melatonin administration. This result reinforces the prospect of therapy with melatonin for synchronization (increased regularity) of endogenous rhythms and improve sleep quality and hence behavior and indicates the actigraphy as a choice tool to characterize several parameters of the activity/rest rhythm of ASD individuals.
\end{abstract}

\section{ARTICLE HISTORY}

Received 8 December 2016

Revised 11 March 2017

Accepted 15 March 2017

\section{KEYWORDS}

Neurodevelopmental disorder sleep; actigraphy; behavior

\section{Introduction}

The Autism spectrum disorder (ASD) is a neurodevelopmental disorder whose main features can be noted in early childhood as a deficit in social interaction and communication and the presence of repetitive behaviors and restricted interests. Among the most comorbidities in ASD, there are sleep disorders (Tudor et al., 2015), which in this population occurs with a frequency of $40-80 \%$ of cases, exceeding the percentage of $20-40 \%$ of children with typical development. The presence of sleep disorders in individuals with ASD may exacerbate associated behavioral disorders and lead to intensification of existing autistic symptoms (Cortesi et al., 2012; Fadini et al., 2015). Among the etiological hypotheses, atypical production of melatonin is one of the theories to explain the high prevalence of sleep disorders in ASD (Glickman, 2010; Johnson et al., 2009). Melatonin is the hormone that marks the dark phase to the body, influencing in human circadian timing (Arendt, 2005) and acting as a sleep modulator (Neto \& Castro, 2008). Under normal conditions, increased sleep and melatonin production are proportional
(Schochat et al., 1998; Tzischinsky et al., 1993), but, in pathological conditions, the atypical production of melatonin may reflect a disruption of other biological functions expressing circadian rhythmicity (Bourgeron, 2007; Pinto et al., 2016).

Studies investigating the use of melatonin in the treatment of sleep disorders in ASD have shown comparative efficiency in sleep charts parameters with little or no side effects (Garstang \& Wallis, 2006). Here we report a case of ASD with non-24hour rhythm and the effect of melatonin on circadian parameters analyzed by actigraphy.

\section{Material and methods}

This study is based on a case report of a 11 years and 4 months old child, male, diagnosed with Asperger syndrome, according to DSM-IV, or mild ASD according to the DSM-IV criteria. The study is in accordance with the Regulatory Norms on Human Research. The study protocol was approved by the ethics committee of the local institution and informed consent was obtained from the parents of 
the participant prior to the start of data collection. At the time of data collection, the boy was attending the 6 th year of elementary school in the morning. The child's mother reported that her son had difficulty initiating and maintaining sleep. At the time, the child was using chlorpromazine $25 \mathrm{mg}$ ( 1 tablet per day - half in the morning and half at night).

The boy was given tablets to be ingested around 30 minutes before bedtime for 30 days. In the first 10 days the tablet consisted of placebo, and in the next 20 days he took melatonin (3 mg). Motor activity was recorded by an actimeter (ActTrust, Condor Instruments), data were downloaded to a computer for time-series analyses according to an algorithm proposed by one of the authors (Gonçalves et al., 2014). The actimeter record was also completed by a sleep diary.

The intermediate stability of the circadian rest/ activity rhythm was calculated on resampled record every 60 minutes. Furthermore, we used Sokolove and Buschel periodogram to identify the periods during the 10 days of placebo and 20 days with melatonin treatment.

To evaluate the behavior we used the child behavior checklist (CBCL) answered by the child's mother (Bordin et al., 2013). The instrument contains several scales: attention, social, thinking, internalizing behaviors (anxiety, withdrawal and somatic disorders), externalizing (rules breaking behaviors and aggression), among others. The inventory was applied three times: before the onset of administration of placebo, after 10 days of placebo use and after 20 days of melatonin administration. The scores are obtained with CBCL and are classified as nonclinical, clinical and borderline.

\section{Results}

The circadian rest/activity rhythm shows an irregular pattern (Figure 1A and 1B) of the first 10 days, during placebo treatment. During placebo administration, the value of the IS was equal to 0.1524 and with the periodogram (Figure 1B) analysis we identified a period of 1340 minutes. In the last 10 days of melatonin use, the value of IS was equal to 0.7235 and the periodogram (Figure 1C) showed that the main rhythm period was 1430 minutes.

On the last day of data collection (after 20 days of melatonin use), the mother reported changes in

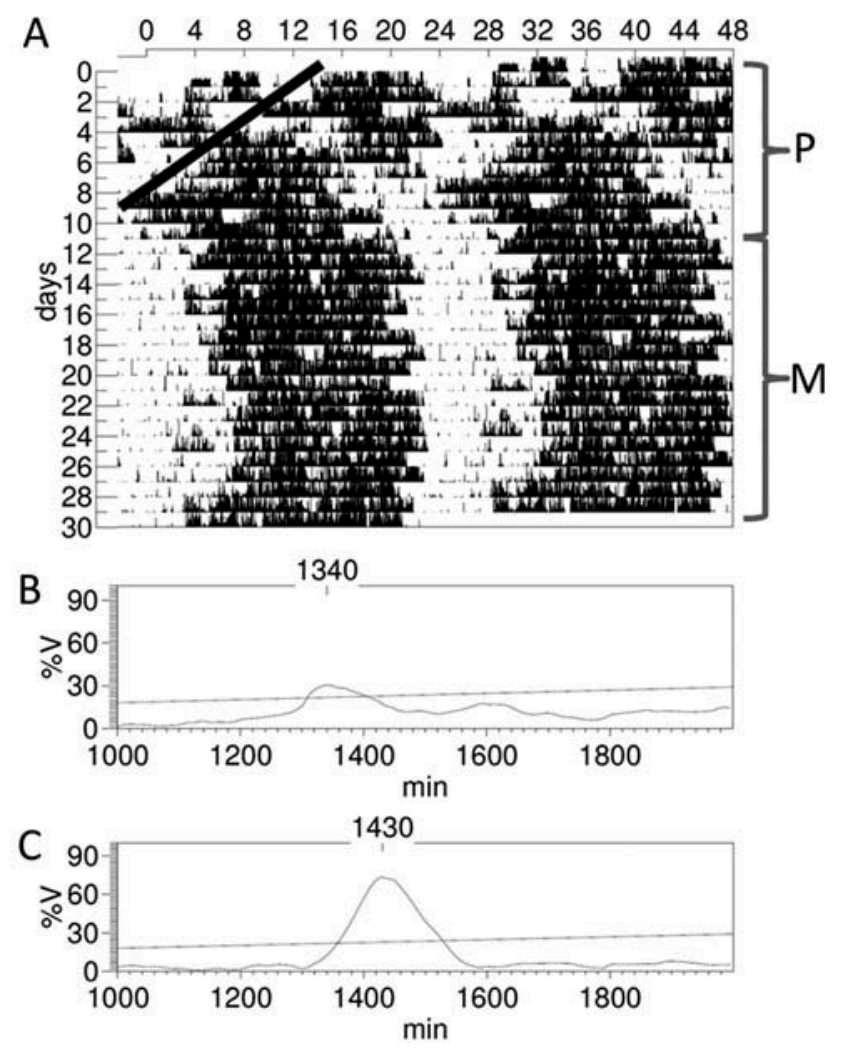

Figure 1. (A) Actogram. A line included in the first 10 days shows that there is a progressive advance in early activity. In the first 10 days the tablet consisted of placebo ( $P$ in figure), and in the next 20 days he took melatonin ( $M$ in figure); (B) periodogram of Sokolove-Buschel for the first 10 days with placebo; (C) periodogram of Sokolove-Buschel for the last 10 days of melatonin use.

the sleep habits of her child, mainly in the last week, with an increase in sleep duration and fewer awakenings during the night (Figure 1).

Behavioral analysis showed that the results remain unchanged after placebo administration; however, after 20 days of melatonin administration some changes were detected according the CBCL. There was improvement in the context of social interactions, which went from a borderline classification to normal, and the problems of thought, which went from clinical condition to normal. On the other hand, the scores of externalizing problems passed the borderline category into the clinic condition classification. The other scales showed no change (see Table 1).

\section{Discussion}

Our results show that melatonin increased approximately 4.7 times the regularity of circadian activity rhythm and resting staying on average 
Table 1. Normal range (Normal), clinical range (Abnormal) or borderline clinical range (Borderline) in the "Child Behavior Checklist for ages 4-18" (CBCL/4-18) parameters after placebo and after melatonin administration.

\begin{tabular}{|c|c|c|c|c|c|c|c|c|c|c|c|}
\hline & \multicolumn{11}{|c|}{ Behavior problems } \\
\hline & Anxious & withdrawn & $\begin{array}{c}\text { Somatic } \\
\text { complaints }\end{array}$ & $\begin{array}{c}\text { Social } \\
\text { problems }\end{array}$ & $\begin{array}{l}\text { Thought } \\
\text { problems }\end{array}$ & $\begin{array}{l}\text { Attention } \\
\text { problems }\end{array}$ & $\begin{array}{c}\text { Delinquent } \\
\text { behavior }\end{array}$ & $\begin{array}{l}\text { Agressive } \\
\text { behavior }\end{array}$ & $\begin{array}{c}\text { Internalizing } \\
\text { behavior }\end{array}$ & $\begin{array}{c}\text { Externalizing } \\
\text { behavior }\end{array}$ & $\begin{array}{c}\text { Total } \\
\text { problems }\end{array}$ \\
\hline Placebo & Borderline & Abnormal & Normal & Borderline & Abnormal & Normal & Normal & Borderline & Abnormal & Borderline & Abnormal \\
\hline Melatonin & Borderline & Abnormal & Normal & Normal & Normal & Normal & Normal & Borderline & Abnormal & Borderline & Abnormal \\
\hline
\end{tabular}

between 00:00 and 06:00. Furthermore, visual analysis of the first 10 days and the periodogram suggest that this patient showed a non-24-hour rhythm.

Subjective data as questionnaires completed by parents and sleep diaries as well as objective data (polysomnography and actigraphy) indicate that the most striking feature of sleep in individuals with ASD is the inability to maintain the required latency with common complaints such as difficulty to initiate and/or maintain sleep, awakenings during the night and deficits during wakefulness (Elia et al., 2000; Miano \& Ferri, 2010).

There are several studies in the literature on the use of melatonin or agonists promoting synchronization in blind patients (Keating, 2016; Sack et al., 2000). Regular use of melatonin should increase the temporal coordination of central and peripheral oscillators (Armstrong et al., 1986). This increase may be responsible for greater regularity of the circadian rhythm and the disappearance of the free-running period after administration of melatonin. In addition, melatonin supports the nocturnal decrease in the body core temperature and facilitates sleep (Arendt, 2005) which explains the improved quality of sleep observed in several studies and reported here by the mother of our subject in the sleep diary and in the CBCL.

The regular rhythm and improvement of the sleep quality of sleep observed after administration of melatonin may be related to behavioral improvement of social interaction and thinking problems observed in this study. The importance of sleep in behavioral aspects in neurodevelopmental disorders has been demonstrated in several studies (Malow et al., 2006; Stores, 2001).

Sleep problems are known to be correlated with behavioral disorders such as attention (Sadeh et al., 2006), anxiety and depression (Cousins et al., 2011), hyperactivity and impulsivity (Touchette et al., 2009). Sleep disorders may be transient or permanent, and could improve the clinical condition in individuals with ASD with interference with behavioral deficits of attention and learning (Johnson et al., 2009). There is a direct relationship between the reduction in sleep duration and severity of behavioral stereotypies, social relationship difficulties, communication disorders and family stress (Miano \& Ferri, 2010; Minkel et al., 2012). Some authors have shown that sleep disorders may be associated with the severity of the ASD and poverty in social interaction (Gianotti et al., 2008; Maski \& Kothare, 2013).

In several conditions where the production of melatonin by the pineal gland is compromised, the exogenous administration of melatonin has brought positive effects in improving the quality of sleep, behavior, attention and memory in animal and human models (Schwichtenberg \& Malow, 2015; Tordjman et al., 2013).

Despite that here we bring a case report study, our results reinforce the prospect of therapy with melatonin for synchronization (increased regularity) of endogenous rhythms and improve sleep quality and hence behavior. Further studies are necessary to clarify if this effect could disappear during a long time of melatonin administration with the necessity of a dose adjust (Braam et al., 2010). In the present study the altered sensory perception of the child did not allow this increased time.

\section{Funding}

This paper was supported by the following grant: CNPq 480208/ 2013-1; BG was supported by CNPq (process 166068 / 2015-2).

\section{Declaration of interest}

The authors report no conflicts of interest.

\section{References}

Arendt J. (2005). Melatonin: Characteristics, concerns, and prospects. J Biol Rhythms. 20:291-303. 
Armstrong SM, Cassone VM, Chesworth MJ, et al. (1986). Synchronization of mammalian circadian rhythms by melatonin. J Neural Transm Suppl. 21:375-94.

Bordin IA, Rocha MM, Paula CS, et al. (2013). Child Behavior Checklist (CBCL), Youth Self-Report (YSR) and Teacher's Report Form (TRF): An overview of the development of the original and Brazilian versions, Cad. Saude Publica. 29:13-28.

Bourgeron T. (2007). The possible interplay of synaptic and clock genes in autism spectrum disorders. Cold Spring Harb Symp Quant Biol. 72:645-54.

Braam W, Van Geijlswijk I, Keijzer H, et al. (2010). Loss of response to melatonin treatment is associated with slow melatonin metabolism. J Intellect Disability Res. 54:547-55.

Cortesi F, Giannotti F, Sebastiani T, et al. (2012). Controlledrelease melatonin, singly and combined with cognitive behavioural therapy, for persistent insomnia in children with autism spectrum disorders: A randomized placebocontrolled trial. J Sleep Res. 21:700-09.

Cousins JC, Whalen DJ, Dahl RE, et al. (2011). The bidirectional association between daytime affect and nighttime sleep in youth with anxiety and depression. J Pediatr Psychol. 36:969-79.

Elia M, Ferri R, Musumeci SA, et al. (2000). Sleep in subjects with autistic disorder: A neurophysiological study. Brain Dev. 22:88-92.

Fadini CC, Lamônica DA, Fett-Conte AC, et al. (2015). Influence of sleep disorders on the behavior of individuals with autism spectrum disorder. Frontiers Human Neurosci. 9:a.347.

Garstang J, Wallis M. (2006). Randomized controlled trial of melatonin for children with autistic spectrum disorders and sleep problems. Child Care Health Dev. 32:585-89.

Gianotti F, Cortesi F, Cerquiglini A, et al. (2008). An Investigation of sleep characteristics. EEG abnormalities and epilepsy in developmentally regressed a nonregressed Children with Autism. J Autism Dev Disord. 38:1888-97.

Glickman G. (2010). Circadian rhythms and sleep in children with autism. Neurosci Biobehav Rev. 34:755-68.

Gonçalves BS, Cavalcanti PR, Tavares GR, et al. (2014). Nonparametric methods in actigraphy: An update. Sleep Sci. 7:158-64.

Johnson KP, Giannotti F, Cortesi F. (2009). Sleep patterns in autism spectrum disorders. Child Adolesc Psychiatry Clin America. 18:917-28.
Keating GM. (2016). Tasimelteon: A review in non-24-hour sleep-wake disorder in totally blind individuals. CNS Drugs. 30:461-68.

Malow BA, Marzec ML, McGrew SG, et al. (2006). Characterizing sleep in children with autism spectrum disorders: A multidimensional approach. Sleep. 29:1563-71.

Maski KP, Kothare SV. (2013). Sleep deprivation and neurobehavioral functioning in children. Int J Psychophysiol. 89:259-64.

Miano S, Ferri R. (2010). Epidemiology and management of insomnia in children with autistic spectrum disorders. Pediatrics Drugs. 12:75-84.

Minkel JD, Banks S, Htaik O, et al. (2012). Sleep deprivation and stressors: Evidence for elevated negative affect in response to mild stressors when sleep deprived. Emotion. 12:1015-20.

Neto JAS, Castro BF. (2008). Melatonina, ritmos biológicos e sono: uma revisão da literatura. Revista Brasileira De Neurologia. 44:5-11.

Pinto AR, Silva RG, Pinato L. (2016). Deglutição orofaríngea na insuficiência renal crônica. CoDAS. 28:71-76.

Sack RL, Brandes RW, Kendall AR, Lewy AJ. (2000). Entrainment of free-running circadian rhythms by melatonin in blind people. N Engl J Med. 343:1070-77.

Sadeh A, Pergamin L, Bar-Haim Y. (2006). Sleep in children with attention deficit hyperactivity disorders: A meta-analysis of polysomnographic studies. Sleep Med Rev. 10:381-98.

Schochat T, Haimov I, Lavie P. (1998). Melatonin: The key to the gate of sleep. Ann Med. 30:109-14.

Schwichtenberg AJ, Malow BA. (2015). Melatonin treatment in children with developmental disabilities. Sleep Med Clin. 10:181-87.

Stores G. (2001). Sleep-wake function in children with neurodevelopmental and psychiatric disorders. Semin Pediatr Neurol. 8:188-97.

Tordjman S, Najjar I, Bellissant E, et al. (2013). Advances in the research of melatonin in autism spectrum disorders: Literature review and new perspectives. Int J Mol Sci. 14:20508-42.

Touchette E, Côté SM, Petit D, et al. (2009). Short nighttime sleep-duration and hyperactivity trajectories in early childhood. Pediatrics. 124:e985-993.

Tudor ME, Walsh CE, Mulder EC, Lerner MD. (2015). Pain as a predictor of sleep problems in youth with autism spectrum disorders. Autism. 19:292-300.

Tzischinsky O, Shlitner A, Lavie P. (1993). The association between the nocturnal sleep gate and nocturnal onset of urinary 6-sulfatoxymelatonin. J Biol Rhythms. 8:199-209. 